This item was submitted to Loughborough's Research Repository by the author.

Items in Figshare are protected by copyright, with all rights reserved, unless otherwise indicated.

\title{
Using the role matrix technique to identify organisational changes: a practical study within London Underground escalators maintenance service
}

PLEASE CITE THE PUBLISHED VERSION

http://dx.doi.org/10.1109/SysEng.2015.7302785

PUBLISHER

(C) IEEE

VERSION

AM (Accepted Manuscript)

\section{PUBLISHER STATEMENT}

This work is made available according to the conditions of the Creative Commons Attribution-NonCommercialNoDerivatives 4.0 International (CC BY-NC-ND 4.0) licence. Full details of this licence are available at: https://creativecommons.org/licenses/by-nc-nd/4.0/

\section{LICENCE}

CC BY-NC-ND 4.0

\section{REPOSITORY RECORD}

Ciocoiu, Luminita, Carys E. Siemieniuch, and Ella-Mae Hubbard. 2019. "Using the Role Matrix Technique to Identify Organisational Changes: A Practical Study Within London Underground Escalators Maintenance Service". figshare. https://hdl.handle.net/2134/19113. 


\title{
Using the role matrix technique to identify organisational changes
}

\author{
A practical study within London Underground escalators maintenance service
}

\author{
Luminita Ciocoiu \\ School of Electronic, Electrical and \\ Systems Engineering \\ Loughborough University \\ Loughborough, UK \\ L.Ciocoiu@lboro.ac.uk
}

\author{
Carys Siemieniuch \\ School of Electronic, Electrical and \\ Systems Engineering \\ Loughborough University \\ Loughborough, UK \\ C.E.Siemieniuch@lboro.ac.uk
}

\author{
Ella-Mae Hubbard \\ School of Electronic, Electrical and \\ Systems Engineering \\ Loughborough University \\ Loughborough, UK \\ E.Hubbard@lboro.ac.uk
}

\begin{abstract}
Increasing financial and service demand pressures drives the London Underground maintenance business to shift its focus from reactive to proactive maintenance. Part of the strategy is to enhance the current condition monitoring capability through the introduction of intelligent remote condition monitoring systems that could provide advisory information regarding the optimum time to undertake maintenance interventions. In this paper we present a case study that utilizes the Role Matrix Technique to identify the organisational challenges associated with the implementation of a health and prognostic assessment system, which uses remote condition monitoring data, within the London Underground escalator maintenance service.
\end{abstract}

Keywords-maintenance; Remote Condition Monitoring; organisational change; enterprise transformation; decision support; Role Matrix Technique

\section{INTRODUCTION}

Current budget constrains and the competitive business environment requires that the transport business becomes more efficient in both delivering services and maintaining the infrastructure necessary for delivering those services. One area where improvements can be made, which can support this business goal, is to enhance the current asset condition monitoring and maintenance management capability. By monitoring the condition of in-service assets (during normal operation) and predicting when maintenance will be required will enable maintenance interventions to be taken at optimum time, in advance of failure. This enhanced capability can positively contribute to increasing the life expectancy of the assets and reducing maintenance costs by eliminating unnecessary interventions.

Within this scope, the 'Health and Prognostic Assessment of Railway Assets for Predictive Maintenance' (HPA) project was created. The project aim is to develop an open architecture system that integrates data from extant Remote Condition Monitoring (RCM) sources and to produce a prognostic assessment via a risk-based Remaining Useful Life (RUL) function [1]. The system is to be utilised within the London Underground escalators maintenance service.
The HPA system is a data-driven software-based tool that calculates the RUL of asset components and provides actionable information regarding optimum time for intervention. The tool will enable better use of the RCM data and improves the quality of extant advisory information resulting from those data.

Having increased capability to assess the in-service condition of assets can enable the organisation to move from a maintenance regime based on reactive and preventative interventions to a condition-based maintenance regime where maintenance interventions are decided based on the health of the asset. This shift in maintenance practices supports the Transport for London (TfL) strategy of improving asset management capability through remote monitoring and management of asset deterioration [2].

The HPA system can undeniably enhance the remote condition monitoring capability of London Underground maintenance business unit. However, there is an increased number of cases reported in the literature where programmes that seek to implement a maintenance regime based on asset condition monitoring, fail to achieve their objectives [3], [4], [5].

What these prior studies consistently note is that aside from the technical challenges associated with the development and implementation of these types of systems, the human and organisational factors have perhaps received less attention [5], [6], and [7]. For example, Jonsson and colleagues [6] investigating the challenges specifically related to the implementation of e-based systems for remote diagnostics found that a key factor in successful introduction of the system is the reorganisation of maintenance routines and business functions based on comprehensive organisational models.

What the case study presented in this paper is concerned with is the identification of those specific organisational and human factors that will affect the development and implementation of the HPA system. For this purpose we employed the Role Matrix Technique (RMT) [8] as a method to identify the changes in activities, roles and responsibilities 
associated with the introduction of the HPA system. The purpose of carrying out this analysis is to issue recommendations for HPA system test and implementation that will guide the organisation to take steps to make the necessary changes to accommodate the insertion of the new technology and achieve the desired outcome.

\section{The Role Matrix TeChNiQue}

The RMT is a paper-based method developed by Siemieniuch and Sinclair [8] with the purpose of defining and visualising the relationships between the roles in a given process. The RMT can be used as a means to promote discussions between process owners and other stakeholders regarding the roles that should be involved in a process and the responsibilities and relationships between them, to ensure that the process is as effective and efficient as it can be [9]. This was the reason why the RMT was considered to be an appropriate method to be used for this particular step in the HPA project, where the involvement of various types of stakeholders was required.

Applying the RMT involves the following steps:

- Definition of roles,

- Development of 'cross-hair diagrams' and

- Creation of the Role Matrix

The first step, definition of roles, consists in identification and definition of all roles involved in the process. A human, a group or team, or an intelligent software agent can perform these roles. As a rule, any agent can hold a single or combination of roles [10].

The second step in the RMT process, development of 'cross-hair diagrams', involves the decomposition of the organisational process into activities and their respective subactivities and allocating the roles to the process activities depending upon the type of responsibility that a role has in a particular activity. For this analysis, four main generic types of responsibilities are considered:

- Controller (controls the activity);

- Executor (executes the work);

- Constraining Advisor (gives advice that is unlikely to be ignored); and

- Discretionary Advisor (gives advice that can be disregarded) [9], [10].

The template for differentiating and allocating the roles within an activity is presented in Fig. 1 .

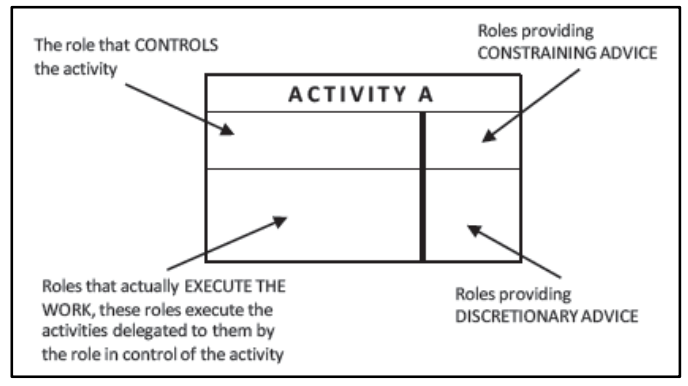

Fig. 1. Role analysis representation, Source: [10].

The third step, creation of the role matrix involves first, the aggregation of the activity diagrams (Fig. 1) to give the overall role analysis for each stage within the given process and second, the transfer of the roles onto a two-dimensional matrix. The matrix is created along two axes, the horizontal axis represents how much discretion a role has in achieving their goal and the vertical axis represents the degree of freedom that the role has in terms of planning, resource allocation and scheduling the activity to achieve the target [9].

The plotting of the roles onto the matrix is based on rules relating to the consideration of the possible relationships that one role can have in relation to other roles involved in the activity [10]. The template for the Role Matrix is presented in Fig. 2.

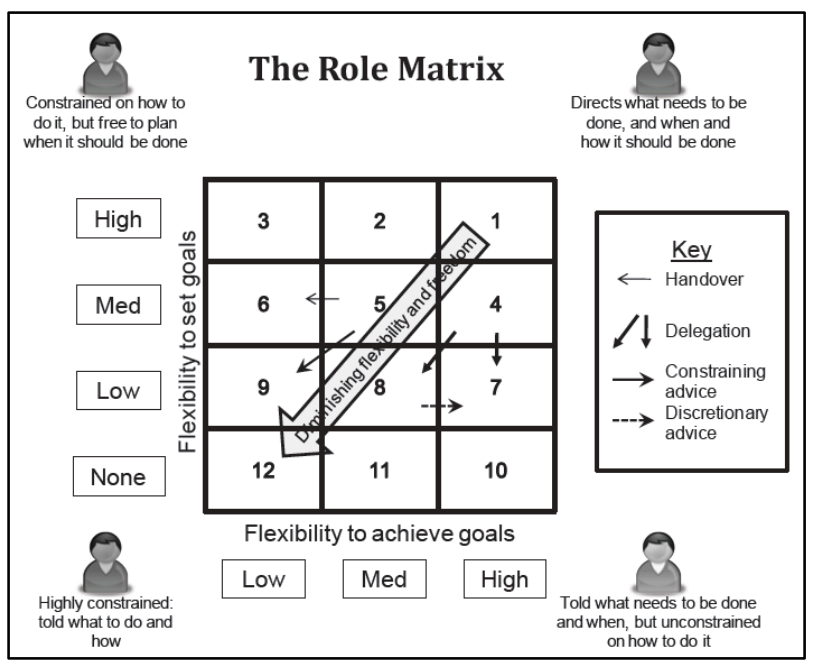

Fig. 2. The Role Matrix, Source: [9].

It is important to note that there is a certain degree of subjective interpretation when aggregating the 'cross hair' diagrams, that subsequently will affect the transfer of the roles into the Role Matrix. As a rule [9], in any overall stage in the aggregation process there can only be one role in control. Therefore, if there are two roles in control of various activities, the role that is in control both for the majority of the time and for the critical activities will be put in control of the overall stage.

Furthermore, when performing the role analysis and transfer of the role to the role matrix, one must have a good understanding of the roles involved in the overall process. Note that how a process is documented and instantiated can differ 
from project to project as the analysts will tailor their approach to suit the needs of the project [9].

\section{THE CASE STUDY}

The case study presented in this paper is part of a wider research study within the HPA project. The overall study looks at the business interfaces and work processes related to the maintenance of London Underground escalators for the Bakerloo, Central, Victoria (BCV) and Sub Surface Lines (SSL) lines in order to produce guidelines for the HPA system testing and integration.

This case study is specifically concerned with the identification of the changes in roles and activities within the maintenance process that may be required given the new capabilities provided by the HPA system. Furthermore, the aim is to involve various stakeholders in the process and promote discussions with the user organisation regarding the most appropriate configuration of roles and activities that will enable the HPA system to be implemented successfully.

\section{A. Data collection}

To collect the data various techniques were used, such as: focus group sessions with stakeholders and analysis of formal documentation. We began by creating a representation of the formal ('Should be') maintenance process. This model was then refined to reflect how the maintenance process was actually executed. Following this analysis, the 'As is' model of the maintenance process was created, based on which the 'As is' Role Matrix was created.

Iteration and gap analysis techniques were used throughout the process to ensure the most accurate representation of each of the models. Furthermore, each of the representations was checked and agreed with the stakeholders.

Based on the 'As is' models and following discussions with the HPA system developers, a representation of the 'To be' maintenance process was created. The 'To be' model was further use to create the 'To be' Role Matrix.

The 'As is' and 'To be' role matrices where then discussed with the user organisation in a joint workshop session. During the workshop, feedback was gathered and used to produce guidance for ongoing organisational development to accommodate the HPA system. It has to be noted that this paper presents the way in which the RMT was utilised and the results of the role analysis: it does not discuss the guidelines issued.

\section{B. Analysis and results}

In the final version of the 'As is' maintenance process, three main stages were identified, each of which was decomposed into a series of sub-activities.

Plan maintenance interventions: Strategic planning of maintenance interventions.

Deliver the maintenance plan: This includes planning of the delivery of the maintenance plan, allocation of resources, carrying out the interventions and reporting.

Review faults and failures: Faults and failures reports are reviewed and corrective and preventative actions are taken.
There are multiple roles involved in the maintenance process, which can vary as the organisation changes. As such, for the purpose of this analysis, a final set of baseline roles were derived and agreed in a similar fashion to the baseline stages of the maintenance process. A brief description of the baseline roles is provided in Table 1:

TABLE I. ROLE DEFINITION FOR THE MAINTENANCE PROCESS

\begin{tabular}{|c|c|c|}
\hline Role & Acronym & Definition \\
\hline Asset Group & $\mathrm{AG}$ & $\begin{array}{l}\text { The asset group is composed of various } \\
\text { managers involved in the maintenance process; } \\
\text { e.g. Asset Manager, Technical Manager, } \\
\text { Planning Manager. The asset group decides } \\
\text { what and when the 'scheduled' interventions } \\
\text { should take place; i.e. perform strategic } \\
\text { planning. }\end{array}$ \\
\hline Planning Team & PT & $\begin{array}{l}\text { Plan the delivery of maintenance interventions; } \\
\text { i.e. allocation of maintenance works, generate } \\
\text { work orders and job packaging. }\end{array}$ \\
\hline $\begin{array}{ll}\text { Duty } & \text { Shift } \\
\text { Manager } & \end{array}$ & DSM & $\begin{array}{l}\text { Oversees day-to-day delivery of maintenance } \\
\text { works; i.e. supervise maintenance } \\
\text { interventions, updates MCC, closes work } \\
\text { orders, reports faults identified during } \\
\text { maintenance interventions. }\end{array}$ \\
\hline $\begin{array}{l}\text { Maintenance } \\
\text { Team }\end{array}$ & MT & $\begin{array}{l}\text { Carry out the maintenance works. Issue reports } \\
\text { following the intervention. Report to DSM. }\end{array}$ \\
\hline $\begin{array}{l}\text { Maintenance } \\
\text { Control Centre } \\
\text { Engineer }\end{array}$ & $\mathrm{MCC}$ & $\begin{array}{l}\text { Handles incidents and fault calls and issues } \\
\text { service requests. }\end{array}$ \\
\hline $\begin{array}{l}\text { Daily Failure } \\
\text { Meeting Team }\end{array}$ & DFMT & Review past $24 \mathrm{~h}$ fault reports and incidents. \\
\hline FRACAS Team & FT & $\begin{array}{l}\text { Review past week fault reports and service } \\
\text { disruption incidents. Establish route cause, } \\
\text { take appropriate actions such as request } \\
\text { monitoring and/or repair work intervention. }\end{array}$ \\
\hline $\begin{array}{l}\text { Condition } \\
\text { Monitoring } \\
\text { Engineer }\end{array}$ & $\mathrm{CME}$ & $\begin{array}{l}\text { Analyse the condition monitoring data (remote } \\
\text { and on-site) and issues condition monitoring } \\
\text { reports. }\end{array}$ \\
\hline
\end{tabular}

Role identification and definition constitutes the first step in the RMT analysis. The second step, development of 'crosshair' diagrams, is to relate the roles to the process activities.

Each activity in the maintenance process was analysed in terms of type of involvement the roles associated with the particular activity have. The type of involvement was differentiated based on the four types of responsibilities defined in Section II: controller, executor, constraining advisor and discretionary advisor.

This analysis was carried out for each of the activities within the maintenance process. The results were then aggregated to give the overall role analysis for each of the three stages within the maintenance process.

To ensure that all the needed interactions between the roles are captured on the process role matrix, the low level activities have been combined following a bottom up approach to form the overall process. The matrix is firstly applied to each subactivity then the matrices are aggregated to form the role matrix for the whole process. 
As mentioned previously, the positioning of the roles within the different sections of the grid involves a certain degree of subjectivity. Essentially, through the positioning of the roles the analyst is 'describing' each role relative to the dimensions of the grid and relative to other roles placed on the grid [9]. The assessment is done based on the relationships between each of the cells in the matrix. These relationships are identified through what is known as 'paste function' [9]. Within this analysis a total of four paste functions have been identified: delegate, offer constraining advice, offer discretionary advice and handover.

The role matrix representation of the 'As is' model is presented in Fig. 3.

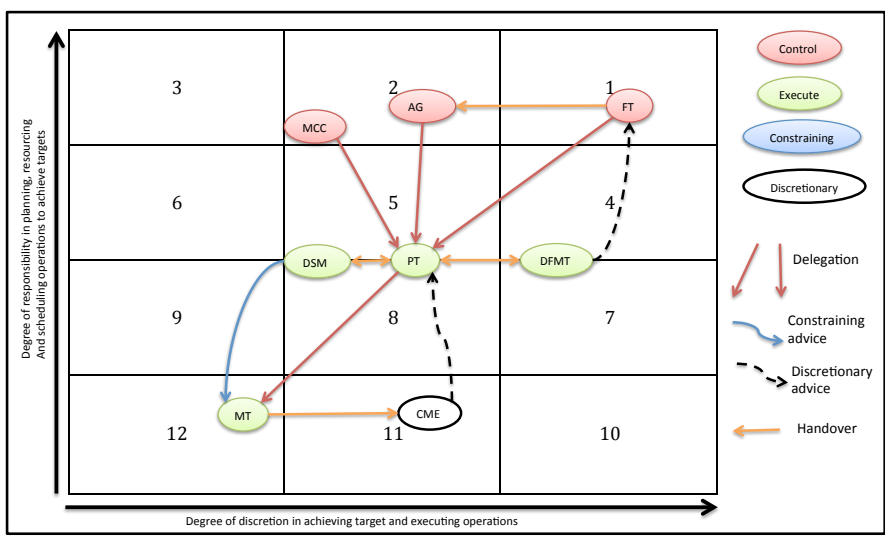

Fig. 3. 'As is' maintenance process

As can be observed in Fig. 3, the current maintenance regime is driven by the strategic planning (AG) of maintenance interventions and by the reaction to failure and faults (FT and $\mathrm{MCC}$ ). The condition monitoring engineer (CME) provides discretionary advice to the planning team (PT), which execute the plan rather than controlling it, and no direct connection exists between in-service condition monitoring and the roles that control the planning of interventions. This characterises the current maintenance regime as being reactive rather than proactive.

The HPA system, which is planned to be introduced to enhance the organisation's condition monitoring capability, creates a new role, the HPA system (as the HPA system can be considered to be an intelligent agent that analysis RCM data and provides advisory information regarding optimum time for maintenance intervention) and new activities within the process (e.g. RCM-based maintenance intervention).

The identified changes in roles and responsibilities are highlighted in Table 2.
TABLE II. ROLE DEFINITION FOR THE NEW MAINTENANCE PROCESS

\begin{tabular}{|c|c|c|}
\hline Role & Acronym & Definition \\
\hline Asset Group & AG & $\begin{array}{l}\text { The asset group is form from various managers } \\
\text { involved in the maintenance process; e.g. Asset } \\
\text { Manager, Technical Manager, Planning } \\
\text { Manager. The asset group decides what and } \\
\text { when the 'scheduled' interventions should take } \\
\text { place; i.e. perform strategic planning. }\end{array}$ \\
\hline Planning Team & PT & $\begin{array}{l}\text { Plan the delivery of maintenance interventions; } \\
\text { i.e. allocation of maintenance works, generate } \\
\text { work orders and job packaging. }\end{array}$ \\
\hline $\begin{array}{l}\text { Duty Shift } \\
\text { Manager }\end{array}$ & DSM & $\begin{array}{l}\text { Oversees day-to-day delivery of maintenance } \\
\text { works; i.e. supervise maintenance interventions, } \\
\text { updates MCC, closes work orders, reports faults } \\
\text { identified during maintenance interventions. }\end{array}$ \\
\hline $\begin{array}{l}\text { Maintenance } \\
\text { Team }\end{array}$ & MT & $\begin{array}{l}\text { Carry out the maintenance works. Issue reports } \\
\text { following the intervention. Report to DSM. }\end{array}$ \\
\hline $\begin{array}{l}\text { Maintenance } \\
\text { Control Centre } \\
\text { Engineer }\end{array}$ & $\mathrm{MCC}$ & $\begin{array}{l}\text { Handles incidents and fault calls and issues } \\
\text { service requests. }\end{array}$ \\
\hline $\begin{array}{l}\text { Daily Failure } \\
\text { Meeting Team }\end{array}$ & DFMT & Review past $24 \mathrm{~h}$ fault reports and incidents. \\
\hline $\begin{array}{l}\text { FRACAS } \\
\text { Team }\end{array}$ & FT & $\begin{array}{l}\text { Review past week fault reports and service } \\
\text { disruption incidents. Establish route cause, take } \\
\text { appropriate actions such as request monitoring } \\
\text { and/or repair work intervention. Analyses HPA } \\
\text { output and maintenance plans if there is a need } \\
\text { to modify the existing plans. Request } \\
\text { amendment of existing interventions of } \\
\text { required; request new maintenance } \\
\text { interventions if required. }\end{array}$ \\
\hline HPA system & Prg.T & $\begin{array}{l}\text { Issue prognostic of RUL based on RCM data } \\
\text { and provides advice regarding optimum } \\
\text { intervention time. }\end{array}$ \\
\hline $\begin{array}{l}\text { Condition } \\
\text { Monitoring } \\
\text { Engineer }\end{array}$ & CME & $\begin{array}{l}\text { Analyses the condition monitoring data (remote } \\
\text { and on-site) and the HPA output, and issues } \\
\text { condition monitoring reports. }\end{array}$ \\
\hline
\end{tabular}

These additional activities and role responsibilities, as well as the new role, will create the need to change the existing configuration of activities and role responsibilities within the maintenance process. To identify these changes we employed the same technique used to identify the existing roles and responsibility and created a 'To be' (version1) role matrix.

The 'As is' and 'To be' (version1) role matrices were then used in a workshop with the user organisation. The matrices were used to facilitate discussions between maintenance process owners regarding possible role configurations within the new maintenance process. The aim was to create a process structure for a given set of roles and to define the relationships between these roles. The results of the workshop were used to produce a 'To be' (version2) role matrix, which is presented in Figure 4. 


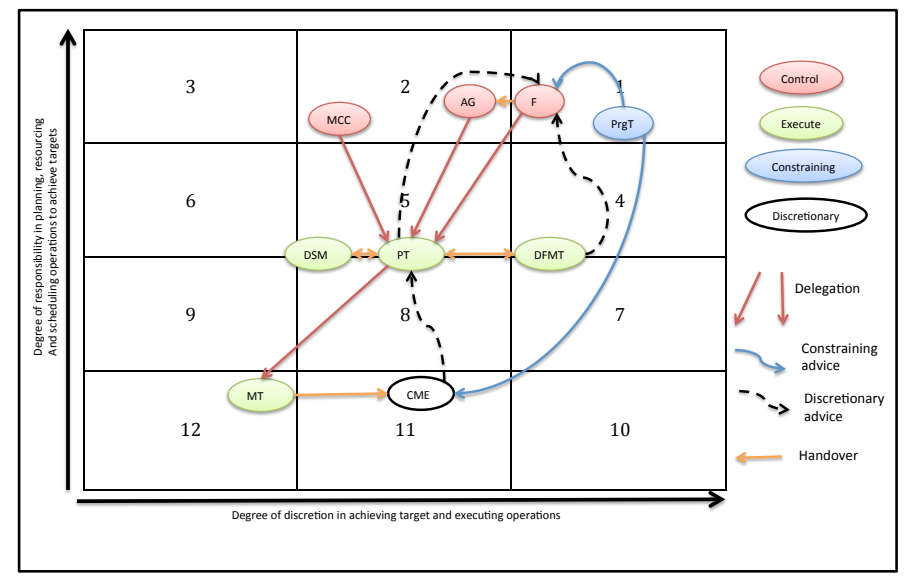

Fig. 4. 'To be' (version2) maintenance process

As can be observed in Fig. 4, the condition monitoring engineer (CME) role has changed slightly within the maintenance process. Because the HPA system will provide enhanced condition monitoring capability, the CME will receive constraining advice from the HPA system. Furthermore, the same constraining advice will be provided to the FRACAS team $(\mathrm{F})$, which will have to take on more responsibility. Beside analysing faults and failures, the FRACAS team will have to analyse, or take into consideration, the health or condition of the escalators while in-service, before issuing maintenance intervention requests. Within this context, the planning team (PT) will provide discretionary advice to the FRACAS team regarding the already planned interventions and resources available, so that an informed decision can be made.

What the RMT revealed that is perhaps surprising is that the planning activities, which the AG, F and PT mainly perform, are not controlled by the HPA system. That is because not all assets are monitored through the RCM system. As a result, the maintenance process cannot shift entirely and immediately towards predictive maintenance. Furthermore, currently the HPA system uses a limited number of variables, based on which it decides when is the optimum time to intervene. As more variables are added and connection made (e.g. with logistics tools) and as trust in the new system is gained, the HPA system could have a more central role within the maintenance process.

\section{FURTHER WORK}

It is important to note that the 'To be' version presented in this paper might not necessarily be the one that will be adopted by the organisation to implement the HPA system and that further consultations with stakeholders (developers and users) have to take place before implementation. This is because of various reasons. Firstly, an organisation goes through a series of stages when implementing a new technology, from testing that technology to actual use of the technology in an integrated way. Secondly, the technology itself can go through various developmental stages while in use (e.g. new functionality added) that will affect its role in the organisation as well as affecting others' roles and the activities carried out by those roles.

\footnotetext{
Sponsors: Innovate UK and Rail Safety and Standards Boards (RSSB).
}

The results of this study are intended to be utilised in further workshops with stakeholders and decision makers to explore alternative configurations of activities and roles involved in the maintenance process. These configurations will serve as the basis for re-engineering the organisational processes for a successful implementation of the HPA system and for the business to achieve the desired goal. The explored options can be the ideal configuration of the organisation as well as intermediary configurations that the organisation may go through in the transformation process from testing of the new technology to implementation.

\section{CONCLUSIONS}

The RMT has been proven to be a straightforward and powerful technique to identify and represent possible organisational changes and potential alternative organisational configurations associated with introduction of intelligent systems, such as the HPA system within the London Underground escalator maintenance part of the business.

The RMT enabled stakeholders to visualise and identify involved roles and responsibilities, information flows, bottlenecks, blockages and other implications associated with introduction of the new technology. As such, the RMT can help vertical integration (decision flow) of the HPA system within the business as well as to support the transition process from the 'As is' to the 'To be' process structure.

The analysis revealed that the changes in the current condition monitoring related roles would have a knock-on effect on the activities involved in the maintenance process. This in turn triggers a change in the responsibilities that the current roles have and therefore will impact the configuration of the activities within the maintenance process and inevitably the timing and positioning of decision points within the system.

The results of this study will further be used to support discussions between stakeholders regarding development of organisational configurations with the purpose of delivering effective and efficient maintenance and in development of the HPA system. Furthermore, the RMT can support the decisionmakers in exploring the cost/benefits of alternative and necessary organisational changes needed for testing and implementing the HPA system.

\section{ACKNOWLEDGMENT}

The authors will like to thank the anonymous reviewers for their valuable comments and suggestions that helped to improve the paper. Furthermore, the authors would like to acknowledge London Underground for their valuable input and feedback and tank the project funding bodies Innovate UK and Rail Safety and Standards Board.

We also like to extend our acknowledgments to the other project partners: Telent, Humaware and University of Nottingham.

The views expressed in this paper are those of the authors and do not necessarily represent those of the other project partners or funding bodies. 


\section{REFERENCES}

[1] TSB, Health and prognostic assessment of railway assets for predictive maintenance, Results of competition: Enabling the digital railway Collaborative R\&D competition, Technology Strategy Board, (2013).

[2] TfL, "Every Journey Matters", PowerPoint presentation, Transport for London, 2014.

[3] R. Mobley, An Introduction to Predictive Maintenance (2nd Edition), Butterworth-Heinemann, 2002.

[4] J. Mitchell, "From vibration measurements to condition based maintenance." Sound and Vibrations 41 (1), 2007, 62-75.

[5] J. Koochaki, and I. M. Bouwhuis, "The Role of Knowledge Sharing and Transactive Memory System on Condition Based Maintenance Policy". IEEE International Conference on Industrial Engineering and Engineering Management, Singapore, 2008.
[6] K. Jonsson, J. Holmstrom, and P. Leven, "Organisational dimensions of e-maintenance: a multi-contextual perspective." International Journal of System Assurance Engineering and Management 1(3), 2010, 210-218.

[7] L. Ciocoiu, E-M. Hubbard, and C. Siemieniuch, "Implementation of Remote Conditioning Monitoring System for Predictive Maintenance: An Organisational Challenge". Contemporary Ergonomics and Human Factors (Ed.), Taylor and Francis. Conference proceedings, 2015.

[8] C.E. Siemieniuch, and M. A. Sinclair, M. A. "On complexity, process ownership and organisational learning in manufacturing organisations, from an ergonomics perspective". Appl. Ergonom. 2002, 33(5).

[9] K. Callan, C. Siemieniuch, and M. Sinclair, "A case study example of the role matrix technique, " International Journal of Project Management, 2006, pp. 506-515.

[10] M. Henshaw, M. Maged, C. E. Siemieniuch, and M. A. Sinclair, "Identification of induced complexity in product service system enterprises". Journal of Enterprise Transformation, 1 (4), 2011, pp. 269289. 